\title{
The Effect of Cervical Stabilization Exercises with Thoracic Spine Extension Exercises on Forward Head Posture
}

\author{
Li-Jun $\mathrm{Yu}^{1}$, Tae-Ho Kim ${ }^{2, *}$ \\ ${ }^{1}$ Department of Rehabilitation Science, Graduate School of Daegu University, South Korea \\ ${ }^{2}$ Department of Physical Therapy, Daegu University, South Korea
}

Received April 6, 2021; Revised June 15, 2021; Accepted June 31, 2021

\section{Cite This Paper in the following Citation Styles}

(a): [1] Li-Jun Yu, Tae-Ho Kim, "The Effect of Cervical Stabilization Exercises with Thoracic Spine Extension Exercises on Forward Head Posture," International Journal of Human Movement and Sports Sciences, Vol. 9, No. 5, pp. 852 - 857, 2021. DOI: 10.13189/saj.2021.090504.

(b): Li-Jun Yu, Tae-Ho Kim (2021). The Effect of Cervical Stabilization Exercises with Thoracic Spine Extension Exercises on Forward Head Posture. International Journal of Human Movement and Sports Sciences, 9(5), 852 - 857. DOI: 10.13189/saj.2021.090504.

Copyright $\odot 2021$ by authors, all rights reserved. Authors agree that this article remains permanently open access under the terms of the Creative Commons Attribution License 4.0 International License

\begin{abstract}
This study was aimed at comparing the effects of cervical stabilization exercises with thoracic spine extension exercises and cervical stabilization exercises with breathing exercises on head posture in subjects with the forward head posture (FHP). FHP is a poor habitual neck posture that is defined by the forward translation of the cervical vertebrae and hyperextension of the upper cervical vertebrae. Continuous FHP adds the load to posterior cervical structures, for instance, ligament, and transforms scapular kinetics and kinematics, and affects the quality of life and activities of daily living. The study included 30 adults with FHP, with 15 participants in each group. The experimental group was asked to perform cervical stabilization exercises with thoracic spine extension exercises, and the control group was asked to perform cervical stabilization exercises with breathing exercises. After 4 weeks of exercise, the changes in head posture (cranial rotation angle and craniovertebral angle) were measured again. Craniovertebral angle and craniovertebral angle were assessed using digital, lateral-view photographs of the subjects in their usual standing postures. The results showed that there was a significant difference between experimental group and control group before and after exercise $(p<0.05)$. In between-group comparison, there were significant differences noted in craniovertebral angle and cranial rotation angle in the experimental group compared to the
\end{abstract}

control group $(p<0.05)$. Both two groups affect cranial rotation angle, craniovertebral angle, and postural alignment, but it is believed that cervical stabilization exercises with thoracic spine extension exercises directly affect the thoracic and cervical spines. As a result, cervical stabilization exercises and thoracic spine extension exercises are recommended to improve postural alignment.

Keywords Breathing Exercises, Cervical Exercises, Forward Head Posture, Stabilization Exercises

\section{Introduction}

A sedentary lifestyle can cause the forward head posture (FHP) [1]. Long-term use of smartphones can lead to the reduction of craniovertebral angle, the abnormal movement pattern of scapula, and forward posture of the head [28]. FHP is a poor habitual neck posture that is defined by the forward translation of the cervical vertebrae and hyperextension of the upper cervical vertebrae [2]. Continuous FHP adds the load to posterior cervical structures for instance, ligament and transforms scapular kinetics and kinematics [3], affects the quality of life and activities of daily living [30]

Previous research demonstrated that cervical 
stabilization exercises have a positive effect on FHP [4-7]. Thoracic stretching exercises can improve postural alignment related to FHP. Various studies have been conducted on thoracic spine extension exercises for kyphosis. These exercises can relieve low back pain and improve lumbosacral alignment [8-11]. Many studies have investigated the result of breathing exercises in the maintenance of proper posture and enhancement of motion ability, and these exercises are being applied as a program to prevent abnormal postures. Breathing exercises are effective in improving the respiratory function and neck posture of those with FHP. In addition, diaphragmatic breathing is often accompanied by relaxation, postural correction, and education [12-16]. Thoracic expansion exercises and abdominal breathing can improve cranial rotation angle (CRA) and craniovertebral angles (CVA) [17]. CVA has been found to increase after cervical stabilization exercises with breathing exercises [16]. Thoracic and cervical strengthening and stretching exercise programs can improve spinal postural alignment by decreasing FHP in subjects [18]. Neck and thoracic extensor strength exercises have a positive effect on the cervical range of motion and FHP [19].

Although there have been many previous studies on FHP, there has never been a direct comparison between cervical stabilization exercises with thoracic spine extension exercises and cervical stabilization exercises with breathing exercises in individuals with FHP.

\section{Methods}

\subsection{Participants}

The number of subjects was calculated by $G^{*}$ power analysis software (ver. 3.1.9.7, Franz Faul, Kiel, GER). The sample size was calculated with 0.05 alpha level, 0.5 effect size and power of $85 \%$. This result indicated that a necessary sample size was at least 29 subjects for my study.
The present study was conducted on 30 subjects with FHP attending D University in Gyeongsan, South Korea. Before participating in the study, all subjects knew about the study and signed the consent form. The Daegu University institutional review committee approved this study (IRB: \#1040621-202007-HR-002).

The inclusion criteria employed were (1) CVA 53 degrees or lower [20] and (2) CRA greater than 143 degrees [22]. The exclusion criteria were (1) mental or cognitive problems that might affect the experiment and (2) subjects with a history of cervical surgery, injury limiting activities, and cervical or thoracic fractures.

There were eight male and seven female participants in the experimental group (EG), with an average age of $20.53 \pm 1.92$ (mean $\pm \mathrm{SD}$ ) years. Their average height, weight, and body mass index (BMI) were $173.23 \pm 9.79$ $\mathrm{cm}, 68.00 \pm 15.55 \mathrm{~kg}$, and $22.46 \pm 3.43 \mathrm{~kg} / \mathrm{m}^{2}$, respectively.

There were seven male and eight female participants in the control group (CG), with an average age of $22.20 \pm$ 2.81 years. Their average height, weight, and BMI were $170.60 \pm 9.62 \mathrm{~cm}, 64.53 \pm 16.58 \mathrm{~kg}$, and $21.90 \pm$ $3.78 \mathrm{~kg} / \mathrm{m}^{2}$, respectively. There was no significant difference in general characteristics between EG and CG.

\subsection{Procedures}

The preparatory experiment began before the formal experiment. The study lasted from September to November 2020.

30 subjects with FHP were selected. They were randomly divided into EG and CG, with 15 subjects in each group. The subjects in the EG performed cervical stabilization exercises with thoracic spine extension exercises, and those in the CG performed cervical stabilization exercises with breathing exercises. Their head postures (CVA and CRA) were measured. After 4 weeks of exercise, the head postures were measured again. 


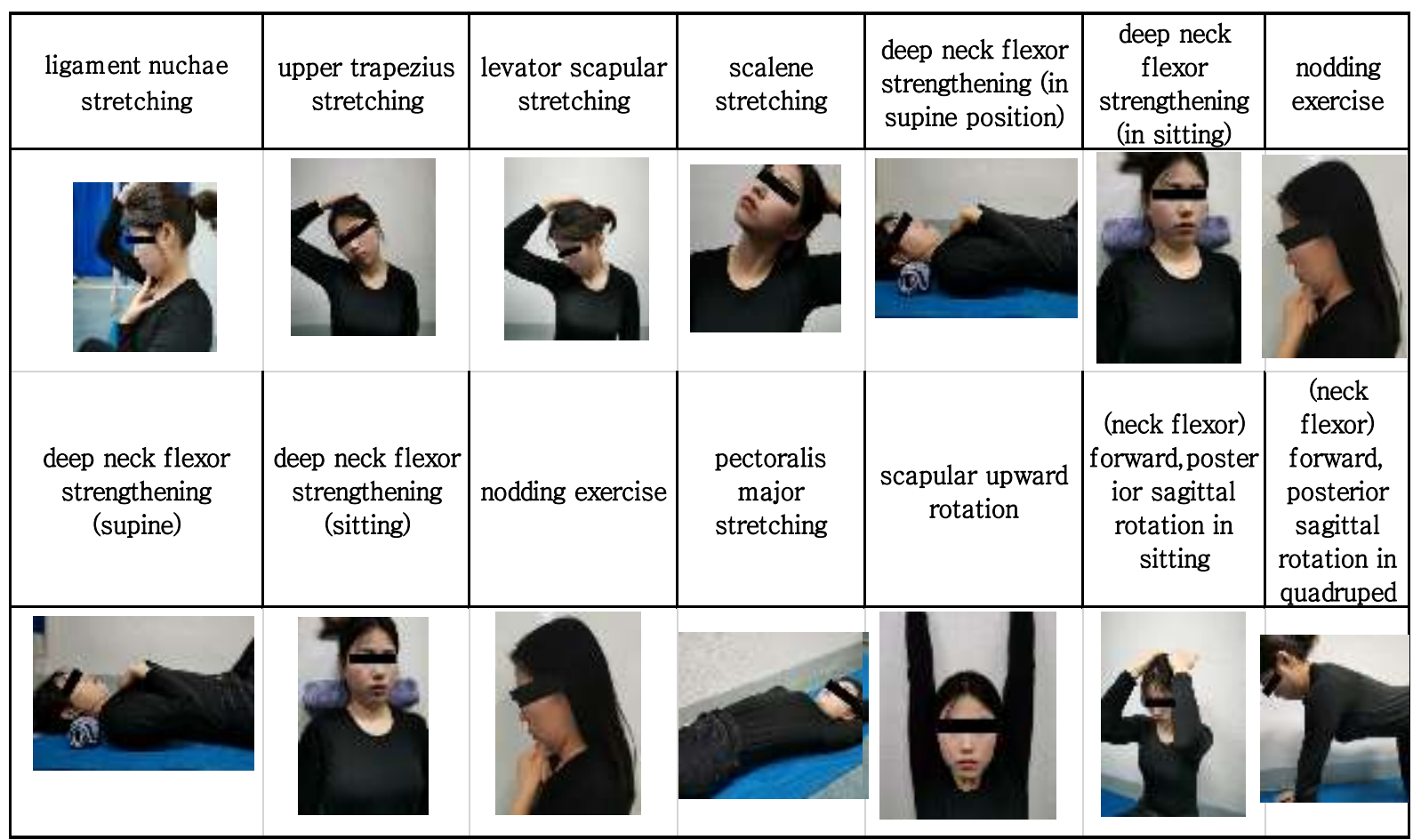

Figure 1. Cervical stabilization exercises

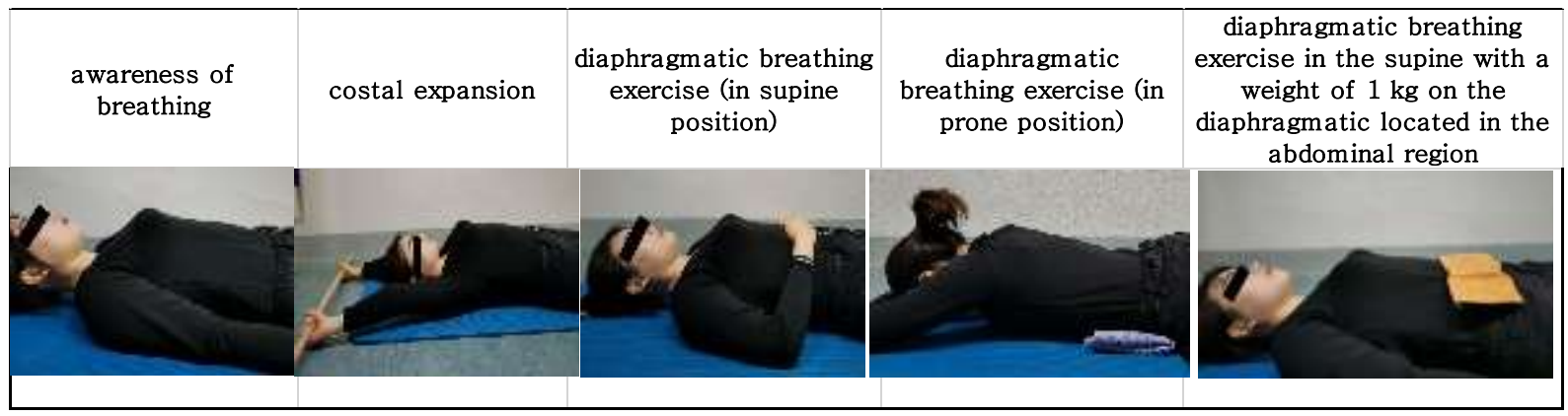

Figure 2. Breathing exercises

\subsection{Assessment}

For change measurement of FHP, CVA and CRA were measured from previous studies [21]. We selected the tragus, C7 spinous process, and the lateral canthus as marker points. The angle formed by the connecting line between the $\mathrm{C} 7$ spinous process and tragus and the horizontal line through the $\mathrm{C} 7$ spinous process is CVA [29]. CRA is the angle formed by the connection line between the tragus and the lateral canthus and the $\mathrm{C} 7$ spinous process and the tragus [22]. CVA and CRA were assessed using digital, lateral-view photographs of the subjects in their usual standing postures [20]. Calculation was performed using an angle measurement software program (Angulus; DPP, Beijing, China ). A mobile camera (Huawei Nova 5i Pro; Huawei Technologies, Co. Ltd., Shenzhen, China) was placed $1.5 \mathrm{~m}$ away at the height of the acromion of each subject [22].

\subsection{Intervention}

\subsubsection{Cervical Stabilization Exercises}

Cervical stabilization exercises comprised two stages: (i) 1-2 weeks in the first stage and (ii) 3-4 weeks in the second stage (Figure 1) [23].

\subsubsection{Breathing Exercises}

Breathing exercises were adopted from previous studies (Figure 2) [24].

\subsubsection{Thoracic Spine Extension Exercises}

Thoracic spine extension exercises were taken from previous studies [25]. Each exercise was performed 15 times as a group and repeated for the two groups (Figure 3) three times a week for 4 weeks. 


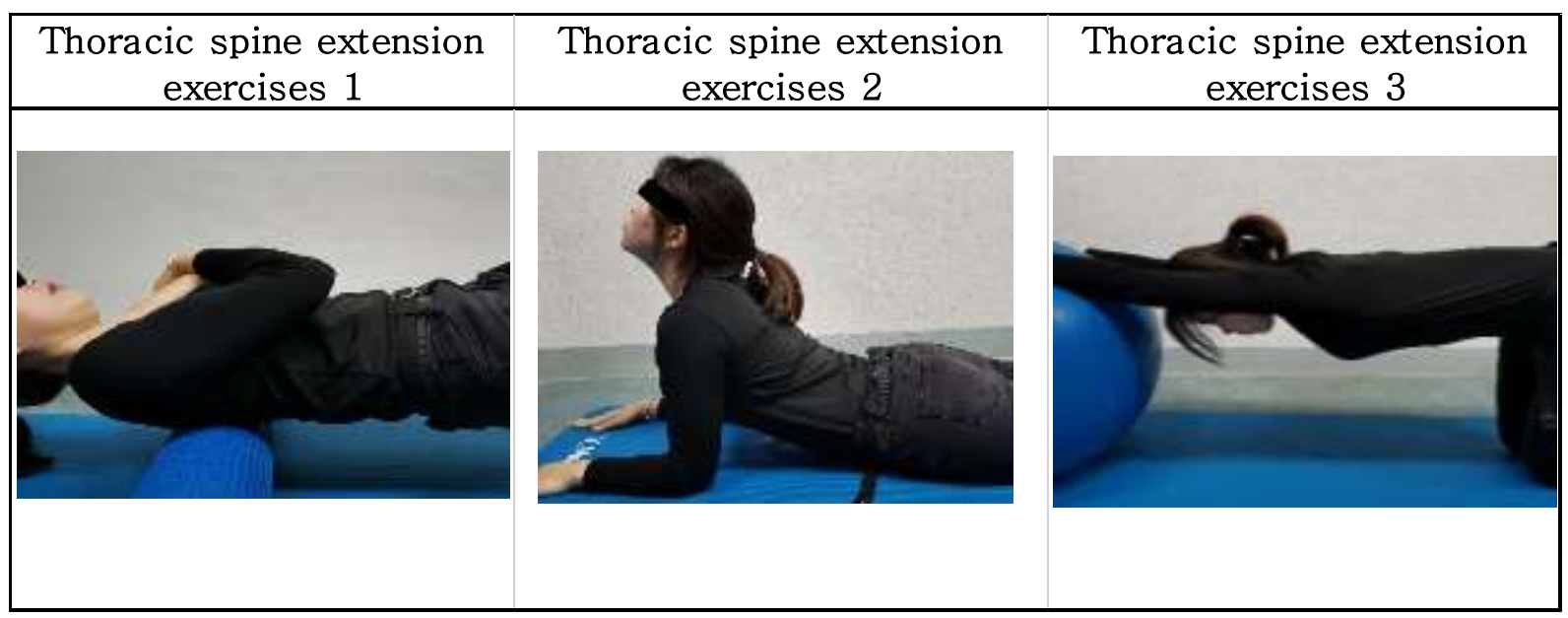

Figure 3. Thoracic spine extension exercises

Table 1. Comparison for CVA and CRA between two groups

\begin{tabular}{|c|c|c|c|c|c|c|}
\hline & & pre & post & $\mathrm{t}$ & $P$ & DV \\
\hline \multirow[t]{4}{*}{$\operatorname{CVA}\left({ }^{\circ}\right)$} & EG & $50.01 \pm 3.54^{\alpha}$ & $56.23 \pm 2.62$ & -6.89 & $.000^{*}$ & $7.26 \pm 2.55$ \\
\hline & CG & $50.42 \pm 2.31$ & $54.38 \pm 2.67$ & -9.47 & $.000^{*}$ & $3.95 \pm 1.50$ \\
\hline & $\mathrm{t}$ & & & & & -4.031 \\
\hline & $p$ & & & & & $.000^{*}$ \\
\hline \multirow[t]{4}{*}{$\mathrm{CRA}\left({ }^{\circ}\right)$} & EG & $150.43 \pm 4.55$ & $140.80 \pm 2.77$ & 8.443 & $.000^{*}$ & $-9.87 \pm 3.63$ \\
\hline & CG & $150.94 \pm 6.95$ & $145.55 \pm 4.35$ & 3.572 & $.004^{*}$ & $-4.48 \pm 2.62$ \\
\hline & $\mathrm{t}$ & & & & & 4.333 \\
\hline & $p$ & & & & & $.000^{*}$ \\
\hline
\end{tabular}

EG: cervical stabilization exercises with thoracic spine extension exercises group

CG: cervical stabilization exercises with breathing exercises group DV: different value

${ }^{\mathrm{a}}$ mean \pm standard deviation ${ }^{*} \mathrm{p}<.05$

\section{Statistical Analysis}

Normality was tested by the Kolmogorov-Smirnov test. The difference within the group before and after the intervention of the EG and CG was analyzed by paired t-test, and the difference between EG and CG determined by independent t-test. SPSS (v.20.0, IBM Corp, NY, USA) was used for statistical analysis, and the statistical significance level alpha is set to $0.05(5 \%)$.

\section{Results}

According to statistics from the paired t-test, after the exercises, CVA and CRA were significantly different in the experimental group (EG) and the control group ( CG ) $(\mathrm{p}<0.05)$ (Table 1).

On the basis of the statistics from the independent t-test, after the exercises, significant differences were noted between CVA and CRA in the EG and CG $(\mathrm{p}<0.05)$
(Table 1)

\section{Discussion}

FHP is becoming increasingly common in day-to-day life, with effects on head posture. This study was aimed at exploring the effects of exercises on head posture.

In this study, there were statistically significant differences found between CRA and CVA in the EG and $\mathrm{CG}$ before and after the intervention. Abdominal breathing exercises were included in the $\mathrm{CG}$, and thoracic exercises were performed in the EG. Cho et al. [18] reported that abdominal breathing and thoracic expansion exercises were effective in improving CVA and CRA. Both groups included cervical stabilization exercises for 4 weeks. Kang et al. [26] demonstrated that cervical exercises were performed for only 4 weeks, and they caused an improvement in FHP.

The cervical stabilization exercise is called the general 
exercise in which various structures that make up the spine are trained to be placed in a neutral position, and thus, the muscles that stabilize the spine by improving flexibility, endurance, and muscle strength are rebuilt [27]. Previous studies reported that cervical stabilization exercises can control FHP [6]. Stretching can increase muscle flexibility [31]. However, in between-group comparison, there was a significant difference between CVA and CRA. These differences were greater in the EG than in the CG. In the EG, the subjects performed thoracic spine extension exercises. While following the thoracic spine extension exercise 1 program, to keep the neck and body in line, the subjects should maintain a deep cervical flexor strengthening posture. Recent reports have shown that strengthening exercises for the deep cervical flexor muscles improved neck and shoulder postures. Deep cervical flexor muscle activation exercises were found to be effective in correcting FHP [14]. Breathing exercises also affect CVA, CRA, and postural alignment, but it is believed that thoracic spine extension exercises directly affect the thoracic and cervical spines.

However, the limitations of this study are also worth noting. The leisure sports activities of the subjects might have affected the experimental results. The study population included only students, not other professional groups. The experimental period was short. In the future, we hope to control other variables more effectively and increase the experimental population and time.

\section{Conclusion}

The study was aimed at comparing the effects of cervical stabilization exercises with breathing exercises and cervical stabilization exercises with thoracic spine extension exercises on head posture in subjects with FHP.

CVA and CRA were found to be significantly improved in the EG. Therefore, cervical stabilization exercises with thoracic spine extension exercises are recommended to improve postural alignment.

\section{REFERENCES}

[1] Cheon S, H., Park S, H, "Changes in neck and upper trunk muscle activities according to the angle of movement of the neck in subjects with forward head posture," J Phys Ther Sci, vol. 29, no. 2, pp. 191-193, 2017. DOI: 10.1589/jpts.29.191

[2] Koseki T., Kakizaki F., Hayashi S., Nishida N., Itoh M, "Effect of forward head posture on thoracic shape and respiratory function, "J Phys Ther Sci, vol. 31, no. 1, pp. 63-68, 2019. DOI: 10.1589/jpts.31.63

[3] Im B., Kim Y., Chung Y, J., Hwang S, J, "Effects of scapular stabilization exercise on neck posture and muscle activation in individuals with neck pain and forward head posture," J Phys Ther Sci, vol. 28, no. 3, pp. 951, 2015. DOI: 10.1589/jpts.28.951

[4] Abdollahzade Z., Shadmehr A., Malmir K., Ghotbi N, "Effects of 4 week postural corrective exercise on correcting forward head posture," Modern Rehabilitation,vol. 11, no. 2, pp. 85-91, 2017. URL: https://doaj.org/article/638442fbac79425b877d74e339fcd4 ac

[5] Pawaria S., Sudan D, H., Kalra S., Yadav J, "Effectiveness of cervical stabilization exercises with feedback on respiratory status in chronic neck pain patients with forward head posture," International Journal of Physiotherapy, vol. 6, no. 3, pp. 70-75, 2019. DOI: 10.15621/ijphy/2019/v6i3/183874

[6] Pawaria S., Sudan D, H., Kalra S, "Effectiveness of cervical stabilization exercises on respiratory strength in chronic neck pain patients with forward head posture-a pilot study," Journal of Clinical \& Diagnostic Research, vol. 13, no. 4, pp. 6-9, 2019. DOI: 10.7860/JCDR/2019/39813.12777

[7] Kim G, C., Hwangbo P, N, "Effects of cervical stabilization exercise using pressure biofeedback on neck pain, forward head posture and acoustic characteristics of chronic neck pain patients with forward head posture," Journal of the Korean Society of Physical Medicine, vol. 14, no. 1, pp. 121-129, 2019. URL: https://doi.org/10.13066/kspm.2019. 14.1.121

[8] De Ridder E., Danneels L., Vleeming A., Vanderstraeten G., Van Ranst M., Van Oosterwijck J, "Trunk extension exercises: How is trunk extensor muscle recruitment related to the exercise dosage?," J Electromyogr Kinesiol, vol. 25, no. $4, \quad$ pp. 681-688, 2015. DOI: 10.1016/j.jelekin.2015.01.001

[9] Woo S, D., Kim T, H, "The effects of lumbar stabilization exercise with thoracic extension exercise on lumbosacral alignment and the low back pain disability index in patients with chronic low back pain," J Phys Ther Sci, vol. 28, no. 2, pp. 680, 2016. DOI: 10.1589/jpts.28.680

[10] Yoo W, G, "Effects of thoracic posture correction exercises on scapular position," J Phys Ther Sci, vol. 30, no. 3, pp. 411-412, 2018. DOI: 10.1589/jpts.30.411

[11] Choi Y, J, "Effectiveness of cervical and thoracic stretching and strengthening exercise to improve forward head posture," Korea University, 2007.

[12] Barker N, J., Jones M., O'Connell N, E., Everard M, L, "Breathing exercises for dysfunctional breathing/hyperventilation syndrome in children," Cochrane Database Syst Rev, vol. 18, no. 12, pp. 5-10, 2013. DOI: $10.1002 / 14651858 . C D 010376 . p u b 2$

[13] Kim E, K., Kang J, H., Lee H, T, “The effect of the shoulder stability exercise using resistant vibration stimulus on forward head posture and muscle activity," J Phys Ther Sci, vol. 28, no. 11, pp. 3070-3073, 2016. DOI: 10.1589/jpts.28.3070

[14] Lee J, C, "The effects of abdominal respiratory exercise by forward head posture adult's respiratory function and respiratory muscle strength," Master's Degree, Daegu University, pp. 35, 2015. URL: http://www.riss.kr.libproxy.daegu.ac.kr/link?id=T1385659 0 
[15] Jang C, "The Effects of Breathing Exercise on Forward Head Posture," Daegu University Graduate School, pp. 91, 2010. URL: http://www.riss.kr.libproxy.daegu.ac.kr/link?i $\mathrm{d}=\mathrm{T} 12138735$

[16] Cho H, R, "Change of craniovertebral Angle (CVA) and respiration on application correction methodof posture and breathing accessory muscle exercise in forward head posture (FHP)," Journal of the Korean Society of Integrative Medicine, vol. 3, no. 3, pp. 89-94, 2015. URL: http://www.riss.kr.libproxy.daegu.ac.kr/link?id=A1012469 62

[17] Ha N, R., Shin H, M., Kim M, C., Oh H, J, "Effects of abdominal breathing and thoracic expansion exercises on head position and shoulder posture in patients with rotator cuff injury," Journal of the korean

[18] society of physical medicine, vol. 11, no. 4, pp. 1-9, 2016. URL: https://doi.org/10.13066/kspm.2016.11.4.1

[19] Choi Y, J., Hwang R, "Effect of cervical and thoracic stretching and strengthening exercise program on forward head posture," The Journal of the Korea Contents Association, vol. 11, no. 10, pp. 293-300, 2011. URL: https://doi.org/10.5392/JKCA.2011.11.10.293

[20] Won D, Y., Kim S, Y., Kim Y, S., Park J, H., Ahn Y, K., Lee Y, K., Jang E, Y., Jeong S, J., Choi S, H., Hyung I, H, "The effects of the neck extensor strength exercise and the thoracic extensor strength exercise on the forward head posture and the cervical rangeof motion," Journal of the Korean Society of Physical Medicine, vol. 18, no. 2, pp. 41-49, 2011. URL: http://www.riss.kr.libproxy.daegu.ac.kr /link?id=A100806372

[21] Lee D, Y., Nam C, W., Sung Y, B., Kim K., Lee H, Y, "Changes in rounded shoulder posture and forward head posture according to exercise methods," J Phys Ther Sci, vol. 29, no. 10 , pp. 1824-1827, 2017. DOI: 10.1589/jpts.29.1824

[22] Kim E, K., Kang J, H., Lee H, T, "The effect of the shoulder stability exercise using resistant vibration stimulus on forward head posture and muscle activity." J Phys Ther Sci, vol. 28, no. 11, pp. 3070-3073, 2016. DOI: 10.1589/jpts. 28.3070

[23] Kocur P., Wilski M., Goliwąs M., Lewandowski J., Łochyński D, "Influence of Forward Head Posture on Myotonometric Measurements of Superficial Neck Muscle Tone, Elasticity, and Stiffness in Asymptomatic Individuals with Sedentary Jobs," J Manipulative Physiol Ther, vol. 42, no. 3, pp. 195-202, 2019. DOI: 10.1016/j.jmpt.2019.02.005
[24] Sahrmann S, Movement system impairment syndromes of the extremities, cervical, and thoracic spines, Elsevier Health Sciences, pp. 51-103, 2015.

[25] Tomas-carus P., Raimundo A., Parraca J, A., Batalha N., Branco J, C., Biehl-printes C, "Breathing exercises must be a real and effective intervention to consider in women with fibromyalgia: a pilot randomized controlled trial," J Altern Complement Med, vol. 24, no. 8, pp. 825-832, 2018. DOI: 10.1089/acm.2017.0335

[26] Kang J, I., Jeong D, K., Choi H, "Correlation between pulmonary functions and respiratory muscle activity in patients with forward head posture," J Phys Ther Sci, vol. 30, no. 1, pp. 132-135, 2018. DOI: 10.1589/jpts.30.132

[27] Kong Y, S., Kim Y, M., Shim J, M, “The effect of modified cervical exercise on smartphone users with forward head posture," J Phys Ther Sci, vol. 29, no. 2, pp. 328-331, 2017. DOI: https://doi.org/10.1589/jpts.29.328

[28] Ryu H, J, "Effects of core exercise and neck stabilizing exercise on proprioception and balance in children with cerebral palsy due to premature birth," Daegu University doctorate thesis, pp. 100, 2015. URL: http://www.riss.kr.libproxy.daegu.ac.kr/link?id=T1385668 0

[29] Akodu A, K., Akinbo S, R., Young Q, O, "Correlation among smartphone addiction, craniovertebral angle, scapular dyskinesis, and selected anthropometric variables in physiotherapy undergraduates," J Taibah Univ Med Sci, vol. 13, no. 6, pp. 528-534, 2018. DOI: 10.1016/j.jtumed.2018.09.001

[30] Singh R., Jagga V., Kaur S, "Effect of Combining Stretcing and Strengthening Exercises of Neck Muscles in Forward Head Posture among Desk Job Operators," Asian Journal of Orthopaedic Research, vol. 5, no. 1, pp. 1-5, 2021. URL: https://www.journalajorr.com/index.php/AJORR/article/vi ew/30151

[31] Mohamed E, E., Elrazik R, K A, "Sustained Natural Apophyseal Glides versus Positional Release Therapy in the Treatment of Chronic Mechanical Neck Dysfunction," International Journal of Human Movement and Sports Sciences, vol. 8, no. 6, pp. 384 - 394, 2020. DOI: 10.13189/saj.2020.080610

[32] Lim W, "Effects of Progressive Increased Intensity of PNF Stretching on Hamstring Force and Flexibility," International Journal of Human Movement and Sports Sciences, vol. 8, no. 5, pp. 186 - 192, 2020. DOI: 10.13189/saj.2020.080505. 